\title{
¿QUÉ DEBEMOS ENTENDER CUANDO OBAMA AFIRMA QUE PRETENDE LLEVAR A CUBA (Y AL MUNDO) LA DEMOCRACIA Y LOS DERECHOS HUMANOS?
}

\section{Paulo Renato Vitória ${ }^{1}$}

RESUMEN: Este trabajo presenta algunas hipótesis, desde una perspectiva crítica y decolonial, sobre qué es lo que debemos entender cuando el presidente estadounidense Barack Obama presenta la intención de su país de llevar a Cuba (y al resto del mundo) la democracia y los derechos humanos. Los métodos utilizados por Estados Unidos para lograr tal objetivo en la mayor de las Antillas han consistido - sobre todo en los últimos 56 años- en hacer justamente lo contrario de lo pregonado en los discursos oficiales: en nombre de la democracia y de los derechos humanos, se ha buscado imponer a Cuba un sistema político controlado por el mercado (y no por la gente) y se ha violado los derechos humanos más básicos de la población cubana. Primeramente, propongo una reflexión sobre el mito del "excepcionalismo" estadounidense, que "condena" ese país a encarnar, propagar y actuar en la defensa de los valores más nobles de la humanidad: la libertad, la democracia, el progreso, los derechos humanos, etc. En seguida, propongo un repaso del mecanismo filosófico-discursivo que permite a los Estados Unidos violar los derechos de los que se oponen a 
su lógica imperial, siempre en nombre de los mismos derechos humanos.

PALABRAS-CLAVE: Estados Unidos; Cuba; "Excepcionalismo" Estadounidense; Democracia; Derechos Humanos.

ABSTRACT: This paper presents some hypotheses, from a critical and decolonial perspective, on what should be understood when US President Barack Obama expresses the intention of his country to bring to Cuba (and the rest of the world) democracy and human rights. The methods used by the US to achieve those objectives in the island consisted, especially in the last 56 years, in doing just the opposite of what is declared in the official speeches. On behalf of democracy and human rights, US pursued to impose to Cuba a political system controlled by the market (and not people) and has violated the most basic human rights of the Cuban population. First, I propose a reflection on the myth of an American "exceptionalism" which "condemns" that country to incarnate, spread and legitimates it to act in defence of the noblest values of humanity: freedom, democracy, progress, human rights, etc. Then, I propose a review about the philosophical mechanism that allows the United States to violate the rights of those who opposes its imperial logic, always in the name of the same human rights.

KEYWORDS: United States; Cuba; American "Exceptionalism" Democracy; Human Rights. 


\section{INTRODUCCIÓN}

Nos orgullece que Estados Unidos ha apoyado la democracia y los derechos humanos en Cuba en estas cinco décadas. (...) Y si bien esta política se originó con la mejor intención, ninguna otra nación impone estas mismas sanciones con nosotros, y ha tenido muy poco efecto más allá de otorgarle al gobierno cubano la lógica para aplicar restricciones sobre su gente. Hoy, Cuba todavía está bajo el gobierno de los Castros y el Partido Comunista que tomó el poder hace medio siglo. (...)

No pienso que podamos seguir haciendo lo mismo durante más de cinco décadas y esperar un resultado distinto. Además, intentar empujar Cuba al colapso no beneficia los intereses de Estados Unidos ni de los cubanos.

Barack Obama

Declaraciones del Presidente sobre cambios en la política con Cuba, 17/12/2014.

El discurso del presidente estadounidense Barack Obama sobre la decisión de restablecer relaciones entre su país y Cuba, despierta algunos interrogantes bastantes oportunos. Si es posible empujar - por más de cinco décadas- un país entero al colapso en nombre de los derechos humanos y de la democracia, ¿serían los derechos humanos y la democracia algo deseable? ¿Qué concepción de derechos humanos y de democracia pueden ser compatibles con la implementación de métodos como invasión militar ${ }^{2}$, sabotajes ${ }^{3}$, atentados 
terroristas ${ }^{4}$, intentos de asesinato al líder de una nación soberana $^{5}$, ataques biológicos ${ }^{6}$, agresiones mediáticas e informativas $^{7}$ y el terrorismo económico ${ }^{8}$ ? ¿Qué es lo que Obama entiende por democracia y derechos humanos?

¿Cómo se da el proceso que les permite a los Estados Unidos imponer dictaduras en nombre de la democracia, violar masivamente derechos humanos en nombre de los mismos derechos humanos, combatir el terrorismo bombardeando civiles o controlar la proliferación de armas nucleares siendo la única potencia en haberlas utilizado contra seres humanos, además de poseer un arsenal capaz de acabar con la vida en el planeta en pocos segundos?

El presente artículo se propone a problematizar los conceptos utilizados por Obama para criticar a la Revolución cubana y reafirmar su objetivo de derrocarla, a través del actual "cambio de métodos". Parto de una reflexión acerca de la construcción de las ideas de América, modernidad y colonialidad, que a su vez permite comprender y desmitificar el presunto "excepcionalismo" estadounidense - defendido por Obama- y algunas otras construcciones míticas acerca de Estados Unidos y la supuesta superioridad de sus valores sobre todos los demás.

A partir de ahí, propongo un breve análisis del proceso denominado por Franz Hinkelammert (1999) como "inversión ideológica de los derechos humanos", problematizando algunos de los fundamentos filosóficos de la concepción de derechos humanos sobre la cual se construyó y se define hasta la actualidad la política imperial de Estados Unidos y hace posible la violación de los derechos humanos en nombre de los mismos derechos humanos, no apenas en Cuba sino en 
todo el mundo. Esbozo también una interpretación de la idea de democracia que subyace a los discursos dominantes hoy en Occidente, para presentar una hipótesis sobre qué debemos entender cuando Obama afirma que pretende llevar a Cuba la democracia y los derechos humanos.

\section{LA CREACIÓN DE AMÉRICA Y EL MODERNO SISTEMA-MUNDIAL ABISAL}

Hoy a menudo se le refiere a Miami como la capital de Latinoamérica. Pero también es una ciudad profundamente estadounidense; un lugar que nos recuerda que los ideales importan más que el color de nuestra piel, o las circunstancias de nuestro nacimiento; una demostración de lo que los cubanos pueden lograr, y la apertura de los Estados Unidos con nuestra familia del sur. Todos somos americanos.

Barack Obama

Declaraciones del Presidente sobre cambios en la política con Cuba, 17/12/2014.

Según Quijano \& Wallerstein (1992, p. 583) la creación de América - como entidad geosocial- "fue el acto constitutivo del moderno sistema mundial". De acuerdo con estos autores, América no ha sido incorporada a una economía-mundo capitalista ya existente, sino que es la condición sin la cual no hubiera surgido una economía-mundo capitalista. Un sistema marcado desde su fundación por el dualismo centro/metrópolis - periferia/colonia y caracterizado por la separación abismal 
(SANTOS, 2009) entre estos dos lados. Mientras el mundo metropolitano se mueve bajo los paradigmas emancipatorios/ regulatorios de la modernidad, el mundo colonial se funda sobre los paradigmas de apropiación/violencia de la colonialidad. Un lado no existe sin el otro. La modernidad y la colonialidad son, por tanto, dos caras de una misma moneda.

Las prácticas de incorporación, cooptación, asimilación y destrucción (física, material, cultural y humana) impuestas por el mundo metropolitano al mundo colonial, aunque invisibilizadas o mitigadas por los discursos dominantes, son condiciones de la afirmación de la idea de "modernidad" y de sus promesas de emancipación, derechos humanos, progreso y libertad. Para Mignolo (2013, p. 35), "La gran mentira (o quizá el gran error y la gran ignorancia, si se prefiere) es hacer creer (o creer) que la modernidad superará la colonialidad cuando, en verdad, la modernidad necesita de la colonialidad para instalarse, construirse y subsistir. No hubo, no hay y no habrá modernidad sin colonialidad." La "conquista" de América es el ingrediente que pone en marcha ese nuevo sistema-mundo capitalista, simultáneamente moderno y colonial, humano y sub-humano, según desde qué lado se lo mire. En palabras de Santos (2009, p. 30), "la humanidad moderna no se concibe sin una sub-humanidad moderna".

Las colonias ibero-americanas, que dieron origen a la mayor parte de lo que conocemos hoy como América Latina y el Caribe, fueron constituidas como periferia del nuevo sistema desde el principio. Los colonizadores discutían si los nativos tenían alma, pero no la superioridad de la racionalidad europea, ni la necesidad de imponerles a los aborígenes 
las "revelaciones" de la "verdadera" religión cristiana". En estas sociedades coloniales coexistían relaciones señoriales semi-feudales entre europeos y nativos, así como algunas prácticas mercantiles. La estructura productiva se organizó en torno a la producción y extracción de bienes primarios, principalmente direccionados al mercado externo, para el costeo de la metrópolis. La "guerra contra los indios" y el pillaje total de sus recursos, eran legitimados por la "sagrada" misión civilizadora de los europeos.

La suerte de las colonias británico-americanas (no de los nativos) fue distinta. Estas fueron concebidas como "sociedad de europeos en tierra americana", siendo el caso "excepcional de una sociedad que se configura directamente, desde sus inicios, como sociedad capitalista, sin los agrupamientos e intereses sociales, instituciones, normas y símbolos que en Inglaterra correspondían aún a la historia señorial" (QUIJANO \& WALLERSTEIN, 1992, p. 589).

La limpieza étnica llevada a cabo por los colonizadores exterminó a la gran mayoría de los indígenas de Norteamérica, los cuales "todavía hoy son ofendidos y calumniados en las películas del Viejo Oeste, donde aparecen como culpables de su propio exterminio". (HINKELAMMERT, 1999). Además, la producción en estas colonias se dirigía prioritariamente a formar y fortalecer un mercado interno y la mano de obra esclava (gratis) no representaba una contradicción en la medida que formaba parte del mismo sistema capitalista, siendo los esclavos africanos una mercancía más. El Estado nacía para controlar y reglamentar las normas - centradas en la defensa de la propiedad privada y de un conjunto de libertades individuales abstractas- pero no era propietario de los recursos ni los controlaba. 
Esas son algunas de las razones que condujeron las dos Américas a caminos tan distintos y desiguales. En beneficio de la síntesis, no profundizaré aquí la discusión de los fundamentos religiosos de la racionalidad economicista acumulativa desarrollada en Estados Unidos (WEBER, 2007), aunque no se puede olvidar la influencia de la doctrina protestante anglosajona en la concepción de trabajo y acumulación (como un deber ante Dios) que se desarrolló en esta nación. No hay duda de que el puritanismo ascético ha favorecido la mitificación de la idea del "excepcionalismo" estadounidense, y la construcción de un imaginario de que el pueblo de Estados Unidos ha sido elegido por Dios para triunfar.

Es importante tener en cuenta que Estados Unidos es concebido como "centro", y no como "periferia" en el sistemamundo moderno/colonial desde su fundación. Rápidamente, entrará en la disputa por el control de las demás colonias del continente Americano, en el marco de la "Doctrina Monroe" (1823) que defendía el lema "América para los americanos ${ }^{10 "} \mathrm{y}$ establecía que cualquier injerencia de los Estados europeos en América sería vista como un acto de agresión que requeriría la intervención de Estados Unidos. Bajo al argumento de defender la independencia de América ante el colonialismo europeo, Estados Unidos se convertía en la nueva metrópolis de la región, que pasaría a considerar su "patio trasero".

Desde muy temprano Cuba ha recibido una atención especial, por parte del vecino del norte, en función de su posición -comercial y militarmente- estratégica en el Mar del Caribe. En el mismo año de 1823, el ex-presidente estadounidense Thomas Jefferson - en una carta al presidente 
Monroe-calificaba a Cuba como "la adicción más interesante que pudiera hacerse a nuestro sistema de Estados" (Apud ZINN, 2005) y el entonces Secretario de Estado John Quincy Adams definía Cuba como una especie de "fruta madura", que, al separarse de España, debería naturalmente caer en manos estadounidenses ${ }^{11}$. Años más tarde, Estados Unidos intervendría en la guerra de independencia cubana ${ }^{12}$ contra los españoles y convertiría a la isla en una suerte de semicolonia (MORGENFELD, 2015). Para retratar ese espíritu expansionista, merece la pena transcribir un editorial del diario The Washington Post, publicado en las vísperas de la entrada de Estados Unidos en la guerra de independencia cubana:

Al parecer, una nueva conciencia se ha apoderado de nosotros - la conciencia de la fuerza - y con ella una nueva apetencia, el anhelo de mostrar nuestra fuerza (...). Sea lo que fuere, la ambición, el interés, la avidez de tierras, el orgullo, el mero placer de combatir, nos anima una nueva sensación. Enfrentamos un extraño destino. La gente apetece el sabor del Imperio en la misma medida que el sabor de la sangre en la jungla (...). (Apud ZINN, 2005).

La rápida expansión — territorial ${ }^{13}$, económica y militarde Estados Unidos, bajo la predominancia de una filosofía individualista y acumulativista, y en condiciones bastante más favorables que en Europa (muchos más recursos naturales y sin las trabas de las tradiciones y relaciones medievales), les permite a las trece colonias británicas asociadas del norte de América terminar el siglo XIX en condiciones de competir 
con Inglaterra por la hegemonía en el comercio mundial y conquistar la condición de potencia imperialista hegemónica al final de la Primera Guerra Mundial ${ }^{14}$.

\section{EL“EXCEPCIONALISMO”ESTADOUNIDENSE Y SUS VALORES UNIVERSALES}

Creo en el excepcionalismo estadounidense con cada fibra de mi ser.

Barack Obama

Discurso en la Academia Militar de West Point, 28/05/2014.

Pero estoy aquí para decir que cuando manifestamos nuestra opinión, lo haremos porque los Estados Unidos de América cree, y siempre representará, un cierto conjunto de valores universales.

Barack Obama Discurso en la VII Cumbre de las Américas, 11/04/2015.

¿Qué es lo que quiere decir Obama cuándo afirma su firme creencia en el "excepcionalismo" estadounidense? ¿De dónde viene esa idea? ¿Cuáles son los "valores universales" mencionados por el mandatario estadounidense? ¿Quién define su contenido? ¿Por qué cree Obama que su país "siempre representará un cierto conjunto de "valores universales"? ¿Pueden otros pueblos del mundo tener otros conjuntos de valores igualmente legítimos (con o sin la pretensión de universalidad)? ¿Pueden otras naciones tener otras maneras 
de entender la democracia y los derechos humanos? ¿Tienen legitimidad los estadounidenses para imponer sus "valores universales" a otros pueblos, incluso a través de la violación/ negación de estos mismos "valores universales" a estos pueblos? ¿Quién le ha dado ese derecho a los Estados Unidos para actuar en nombre de toda la humanidad?

La construcción - por parte de los Estados Unidos- de un poderío militar, informativo y cultural sin precedentes en la historia de la humanidad ha servido para mitificar las profecías de sus fundadores, como si su "suceso" económico y consecuente hegemonía mundial fuera un "destino manifiesto", necesario e inevitable. Según Friedman, el mito del "excepcionalismo" estadounidense, se basa en "la firme creencia de que Estados Unidos representa la encarnación de los principios más sagrados de la sociedad humana: la libertad, la democracia y el progreso". (FRIEDMAN, 2015). La explicación es tautológica: Estados Unidos triunfa porque defiende los mejores valores. Sus valores son los mejores porque comprobadamente conducen al triunfo. No se discute ni el contenido de sus "valores universales" ni las complejas $-\mathrm{y}$ no necesariamente justas - condiciones que posibilitan su "triunfo".

Identificar esos "principios más sagrados de la sociedad humana" a una sola nación permite también que se interprete cualquier conducta crítica a este conjunto de valores o a las políticas imperialistas de Estados Unidos no apenas como "irracionales", contrarias a la libertad, a la democracia y al progreso, sino también como "antiamericanas". El "antiamericanismo" funciona como un escudo para invertir la relación causa-efecto: las críticas al imperialismo o la 
proposición de otros principios diferentes se convierten en ataques pasionales, hostiles o envidiosos ${ }^{15}$ y no llegan a ser comprendidas como consecuencia (o reacción) ante la imposición, muchas veces violenta, de los "valores universales" de la modernidad/colonialidad occidental, sobre todo por parte del imperialismo estadounidense, fruto maduro de ese proyecto civilizatorio.

En la interpretación ideológica que hace Obama del "excepcionalismo" estadounidense, lo que se oculta -intencionalmente o no-es exactamente todo lo que queda al “otrolado dela línea abisal", antes mencionada(SANTOS, 2009). Se visibiliza apenas los logros y los progresos materiales, los avances en derechos y garantías individuales y la construcción de un modo de vida basado en un nivel promedio de consumo muy elevado. Se oculta el hecho de que el "triunfo" de Estados Unidos solo se hizo posible en función de diferentes alianzas estratégicas, muchas veces manifiestamente contrarias a los "valores universales" presentes en sus discursos, además del desprecio al derecho internacional, a la soberanía y a la autodeterminación de muchos pueblos, la imposición de acuerdos y tratados comerciales asimétricos ${ }^{16}$ con países más débiles, el patrocinio y apoyo material a golpes de Estado ${ }^{17}$ contra gobiernos democráticos, la explotación (neo)colonial, el pillaje neoliberal y la masiva violación de los derechos de otros pueblos, incluidos bombardeos atómicos, químicos y biológicos, los secuestros realizados por la CIA en diversas partes del mundo y los campos ilegales - y extraterritorialesde detención y tortura, como los de Abu Ghraib y Guantánamo, los ataques con vuelos no tripulados y un largo etcétera, bajo una obscena y vergonzosa impunidad ${ }^{18}$. Todo eso siempre 
en nombre de su visión - muy particular, por supuesto- de democracia y de los derechos humanos. Por lo tanto, es muy importante tratar de entender y cuestionar dichos conceptos desde una gramática decolonial ${ }^{19}$.

\section{¿QUÉ DERECHOS HUMANOS?}

Y ya sea que se traten de represiones en contra de la libertad de expresión en Rusia o China, o restricciones de libertad de asociación y reunión en Egipto, o campos de prisión a cargo del régimen de Corea del Norte, los derechos humanos y libertades fundamentales aún están en riesgo alrededor del mundo. Y cuando eso sucede, creemos que tenemos una obligación moral de manifestarnos.

Barack Obama

Discurso en la VII Cumbre de las Américas, 11/04/2015.

¿Qué significan los derechos humanos para el gobierno de Estados Unidos? ¿Cómo se ha desarrollado el proceso que le permite a este país violar derechos humanos de cualquiera que contraríe sus intereses, actuando en nombre justamente de los derechos humanos? ¿Qué es lo que debemos entender cuando Obama afirma que pretende proporcionar a Cuba los derechos humanos?

Según Franz Hinkelammert, la clave para entender la ambivalente concepción dominante en esta nación sobre el contenido de tales derechos está en la filosofía política de John Locke (1632-1704), "quien hasta hoy es considerado el 
padre de la patria y de los derechos humanos desde el punto de vista estadounidense." (HINKELLAMERT, 1999, p. 35). Más específicamente, en el Segundo tratado sobre el gobierno civil $^{20}$, escrito en 1690.

Se trata de un libro fundante, de transcendental importancia para la tradición occidental, sobre todo anglosajona, de derechos humanos. Un texto que sintetiza la experiencia vivida en Inglaterra en el proceso que desembocó en el triunfo de la Revolución Gloriosa de 1688, que eliminó definitivamente el potencial popular (incluso, de cierto modo, socialista $^{21}$ ) de la revolución iniciada en 1648-49, y consolidó una revolución incontestablemente burguesa, aunque preservando la monarquía. A diferencia de Inglaterra, Estados Unidos era una tierra amplia, rica en recursos y posibilidades de expansión hacia los dos grandes océanos, con una población nativa "desechable", y sobre todo libre de un pasado (dentro de una visión eurocéntrica, por supuesto).

Echemos un rápido vistazo a los principales argumentos de la teoría de Locke. Para este filósofo, los derechos humanos naturales son el derecho a la vida, salud, libertad y propiedad ${ }^{22}$ (LOCKE, 2006, §6) ${ }^{23}$. Estas son fruto de la "razón y la equidad común", las "normas que Dios ha establecido para regular las acciones de los hombres en beneficio de su seguridad mutua". (LOCKE, 2006, §8)".

Para Locke, el poder político es "el derecho de dictar leyes bajo pena de muerte y, en consecuencia, de dictar también otras bajo penas menos graves, a fin de regular y preservar la propiedad y emplear la fuerza de la comunidad en la ejecución de dichas leyes y en la defensa del Estado frente a injurias extranjeras". (LOCKE, 2006, §3). En el caso de que alguien 
trasgreda esas normas, está voluntariamente declarando "guerra contra todo el género humano (...) y, por lo tanto, puede ser destruido como si fuera un león, un tigre o una de esas bestias salvajes entre las cuales los hombres no pueden vivir ni encontrar seguridad". (LOCKE, 2006, §11).

La definición del derecho de propiedad como un derecho fundamental posibilita a la teoría de Locke invertir los derechos humanos ideológicamente. Para que una persona sea digna de pertenecer al género humano - y tenga, por lo tanto, derechos humanos-, debe reconocer y respetar la validez absoluta y universal de una forma específica de propiedad, privada, individual e inviolable. Pero no es cualquier ser humano que tiene derecho a tener propiedades. Para Locke, solo el "hombre trabajador racional" (este entendido desde una moral puritana y eurocéntrica) puede ser propietario (LOCKE, 2006, §34).

El que se opone a ese derecho humano universal -o que tiene otra forma diferente de entender las relaciones sociales y entre los seres humanos y la naturaleza que no sea la burguesaestá declarando guerra contra todo el género humano y puede ser aniquilado como una "bestia salvaje", precisamente en nombre de los derechos humanos. Ahí también podemos encontrar la raíz del concepto de "intervención humanitaria", muy utilizado en la actualidad.

Quizás el término "bestia salvaje” parezca muy duro. Pero pensemos un momento sobre la imagen que se ha construido internacionalmente acerca de la figura del líder de la Revolución Cubana a lo largo de los últimos 56 años en todo el mundo. Fidel Castro es retratado casi unánimemente por los medios de información occidentales como un dictador, 
cruel, que no respeta los derechos humanos, casi una "bestia" (quizás, para muchos, peor). Posiblemente por eso lo intentaron aniquilar tantas veces. No importa que en Cuba - a pesar de las agresiones externas - todas las personas tengan derecho a la vida, a la educación, a la salud, a una vivienda, y sean igualmente propietarias de los medios fundamentales de producción.

No importa que, pese a todas las agresiones - en nombre de los derechos humanos-, el pueblo cubano haya resistido y defendido su Revolución por tanto tiempo. Cuba sigue siendo una nación que no respeta los derechos humanos y los Estados Unidos tienen una "obligación moral" de manifestarse. En las palabras de Hinkelammert (1999):

El violador de los derechos humanos es transformado en un monstruo, una bestia salvaje que se puede eliminar sin que haya la más mínima cuestión de derechos humanos. Pierde hasta el carácter de ser humano. La relación es como aquella entre San Jorge y el dragón. La responsabilidad por el aniquilamiento la tiene quien es aniquilado. Quien aniquila, en cambio, tiene el poder e igualmente el honor de respetar los derechos humanos.

El que detiene el poder de informar y de destruir masivamente tiene el poder de determinar quiénes son los seres humanos y quiénes son las "bestias salvajes", caracterizando a sus enemigos como "violadores de los derechos humanos". En tal perspectiva, la guerra de los defensores de los derechos humanos será siempre una guerra justa. A través de ese mecanismo, es posible aniquilar a cualquiera que se meta en el camino del que defiende toda la humanidad. 


\section{¿QUÉ DEMOCRACIA?}

El apoyo de Estados Unidos a la democracia y los derechos humanos va más allá del idealismo, es un asunto de seguridad nacional. Las democracias son nuestros amigos más cercanos y están mucho menos dispuestos a ir a la guerra. Las economías basadas en los mercados libres y abiertos tienen mejor desempeño y se convierten en mercados para nuestros productos.

Barack Obama

Discurso en la Academia Militar de West Point, 28/05/2014.

El mismo poder que permite (a los detentores de las armas de destrucción e información masivas) definir quiénes son los seres humanos y quiénes son las "bestias", sirve también para determinar cuáles sistemas políticos son democráticos y cuáles no. Y el mecanismo para hacerlo es bastante similar al descrito anteriormente. Así como sólo tienen derecho a tener derechos humanos los que respetan los derechos humanos, sólo merecen la democracia los países que respetan la democracia. Todo dentro de una visión muy particular y limitada de democracia y derechos humanos, por supuesto.

¿Sería - para Obama- la democracia un "gobierno del pueblo, por el pueblo y para el pueblo" 24 , cuyo contenido material varía conforme la voluntad de los propios sujetos (el pueblo) o sería más bien un sistema materialmente limitado a garantizar "las economías basadas en los mercados libres y abiertos", apenas formalmente legitimado por el voto popular? ¿Puede un pueblo decidir democráticamente seguir un camino distinto al del "libre mercado"? ¿Puede una 
democracia reconocer otras formas diferentes de propiedad y privilegiar otras relaciones sociales y ambientales? ¿No sería precisamente antidemocrática la pretensión de imponer un contenido obligatorio como requisito para considerar un determinado gobierno democrático?

Según el sociólogo Aurelio Alonso (2015), la democracia "Significa para Obama la adopción del esquema multipartidista liberal que la confina a un acontecimiento electoral periódico, alrededor del cual elabora el mundo del capital su ritual político." En el mismo sentido, para el filósofo Carlos Fernández Liria (2004):

Los ciudadanos de nuestras democracias parlamentarias, por ejemplo, no se representan $-\mathrm{y}$ con toda razón $-\mathrm{al}$ Parlamento como un espacio para la argumentación y contraargumentación, sino como un espacio para la negociación de intereses entre distintas facciones de una casta especial, la de los políticos, que es, a su vez, una especie de correa de transmisión de grandes corporaciones económicas que dirimen en el espacio político sus correlaciones de fuerzas, de las cuales depende, en realidad, todo lo verdaderamente importante.

Parece posible descomponer la concepción de democracia defendida por Obama (y por los discursos dominantes, en general) en por lo menos dos aspectos distintos, interconectados entre sí: uno formal y otro material, siendo el segundo muchísimo más importante que el primero.

Formalmente, se entiende - desde esa perspectivaque es "democrático" un gobierno que sea electo por el voto universal, directo, periódico, libre y secreto, con la libre 
concurrencia de diferentes partidos políticos. El voto legitima formalmente el gobierno elegido por el pueblo, que en teoría representa a la soberanía popular.

Materialmente, esa concepción de "democracia" puede ser entendida como un sistema político que no coloque obstáculos legales a la mercantilización del mayor número posible de cosas (naturales, sociales y humanas, incluidos los bienes esenciales para la vida) y no ponga trabas o amenace la estrategia geopolítica de preservar la hegemonía estadounidense ${ }^{25}$ en el mundo (que le permite operar en el sistema-mundo capitalista en condiciones extremadamente ventajosas).

Hay, en las democracias liberales, diversos mecanismos formales que sirven como "válvula de seguridad", para garantizar el respecto a estos límites materiales, neutralizando - dentro de lo posible- las contingencias que pueden llevar a las mismas a adoptar rumbos diferentes a los deseados. Por ejemplo, la financiación privada/corporativa de las campañas electorales $^{26}$ (toda "donación" es también una inversión), la legalización de los lobbies, la separación de los poderes ${ }^{27}$, el control privado de los medios de comunicación de masas ${ }^{28} y$ la represión violenta de la actividad política al margen de las instituciones formales, entre otros dispositivos.

Mientras más sometido esté un sistema político al control por parte de los intereses privados, corporativos y financieros transnacionales y útil al mantenimiento de la hegemonía imperialista, más democrático será considerado ese sistema político para el discurso dominante. Una economía "abierta", dócil, controlada por el mercado, asociada y legitimada por un proceso electoral formal es el modelo ideal a ser perseguido desde este pensamiento. 
El criterio formal puede faltar sin que haya cualquier tipo de presión por parte de Estados Unidos (y de los demás "guardianes" de la democracia). De hecho, ese país tiene muy buenas relaciones con diversos gobiernos que no cumplen las exigencias democráticas formales pregonadas (desde que cumplan el criterio material). Ahora, si un gobierno resulta electo conforme a estos requisitos, pero decide poner en marcha un proyecto político que retira el poder del mercado - sin romper ninguna institución formal y con respaldo popular-, nacionalizando los recursos naturales e implementando procesos de participación y control ciudadano (más allá del voto) insubordinados al control económico, pasa a representar - paradójicamente una amenaza a la democracia. Ni hablar de un gobierno que lo hace a través de una ruptura radical del orden burgués, como lo hizo Cuba.

Todo lo que afronte el mercado es considerado "totalitarismo", "inmadurez" 29 y frecuentemente es asociado al ya mencionado "antiamericanismo" (otro término despreciativo que está de moda en América Latina y en el sur de Europa es "populismo"). Para restaurar la "democracia", (en su sentido material arriba mencionado), todos los medios son válidos: promoción de campañas desestabilizadoras, financiación de grupos opositores (electorales o no), sanciones económicas, boicots, apoyo a golpes de Estado, hasta intervenciones militares directas o a través de ejércitos mercenarios o grupos paramilitares.

Estoy seguro de que cualquier lectora o lector de este trabajo podrá elaborar un largo listado de ejemplos muy concretos - históricos y actuales-, provenientes de varias 
partes del planeta, que ilustran y comprueban lo dicho hasta aquí. Cualquier listado que se haga en este espacio será incompleto y a la vez ocupará muchas páginas, razón por la cual prefiero invitar a las eventuales lectoras y los eventuales lectores de este texto a elaborar su propio listado de ejemplos de la doble moral estadounidense con relación a la democracia - paradoja denominada por Friedman (2015?) como "antiamericanismo democrático y los antidemócratas proamericanos".

La concepción estadounidense de democracia contiene una cláusula no necesariamente escrita que amputa la soberanía y la autodeterminación política, económica y social de los demás pueblos del mundo, una vez que delimita de antemano el margen posible de ejercicio del poder por parte de los ciudadanos de otros países.

Independientemente de las eventuales imperfecciones existentes en el sistema político cubano (tanto en su diseño institucional cuanto en la práctica), cuando los representantes del gobierno estadounidense o los medios de comunicación corporativos critican a Cuba por falta de democracia o de derechos humanos, seguramente no están preocupados en mejorar los espacios de participación popular existentes en Cuba, ni tampoco en ampliar el acceso de las población cubana a los "bienes necesarios a una vida digna" (HERRERA FLORES, 2009, p. 108). Lo que quieren es justamente lo contrario, apoderarse de la democracia cubana y someterla al control del mercado en detrimento de las personas. Y transformar sus derechos en mercancía, para quien pueda pagar. 


\section{CONSIDERACIONES FINALES}

La estrategia utilizada hasta ahora por los sucesivos gobiernos estadounidenses para destituir la Revolución Cubana y apoderarse de la isla, al mismo tiempo en que golpearon duramente a la población de ese país, violando sus derechos más básicos, sirvieron también para aislar Estados Unidos de los demás países del continente, sobre todo a partir de los procesos de integración soberana antiimperialista impulsados por el ex-presidente venezolano Hugo Chávez Frías, fallecido en 2013, y por los países del ALBA-TCP, entre los cuales se encuentra Cuba. El rechazo a las agresiones a Cuba es prácticamente unánime en el mundo, incluso entre los aliados más prójimos a Estados Unidos y es creciente dentro de este país. Eso lo admite abiertamente Obama en sus discursos aquí mencionados.

Pero, sin duda, el cambio de estrategia contra Cuba debe ser entendido también contextualmente, desde una perspectiva geopolítica y geoestratégica más amplia. Forma parte de una ofensiva política, económica y militar (ARKONADA, 2015) en diversas partes del planeta para contener las crecientes amenazas a su dominación imperial. La consistente ascensión económica de China y la recuperación (económica y moral) de Rusia, dos potencias que vienen estableciendo relaciones importantes no apenas en América Latina y el Caribe, sino también construyendo posibles alternativas al actual sistema financiero internacional, controlado monopolísticamente por Estados Unidos, también son ingredientes de trascendental importancia en el giro de ese país hacia Cuba. 
Recuperar el control de Cuba es un paso clave en la estrategia para mantener la hegemonía estadounidense en el continente, siendo el dominio de su idealizado "patio trasero" esencial para el mantenimiento de su hegemonía global. En Nuestra América, dicha ofensiva ha gravitado fundamentalmente en torno al recrudecimiento de la presencia militar estadounidense en el continente (bajo el pretexto de la -fallida e hipócrita - guerra a las drogas), el espionaje, las duras campañas de desestabilización mediática, la financiación de grupos opositores (no necesariamente electorales) como forma de injerencia y la guerra económica ${ }^{30}$.

Tales estrategias han contribuido decisivamente para los golpes de Estado contra Zelaya en Honduras (2009), Lugo en Paraguay (2012) y Rousseff en Brasil (2016), para la renuncia de Pérez Molina en Guatemala (2015), para las recientes derrotas electorales en Venezuela y Argentina, ambas a fines de 2015, y para el triunfo del "no" en el más reciente referéndum boliviano (KARG, 2016). También han servido para agravar la crisis política en Ecuador, por poner apenas ejemplos.

Derrocar a la Revolución Bolivariana y los gobiernos más radicales de Bolivia, Ecuador y Nicaragua son pasos fundamentales de esa ofensiva ${ }^{31}$. Impulsar los tratados bilaterales asimétricos, mal llamados tratados de "libre comercio", impedir la consolidación de la presencia china en la región (actualmente hay una ofensiva contra la construcción de un canal interoceánico en Nicaragua con capital chino), provocar cambio estructurales de carácter neoliberal en Brasil, para debilitar a los BRICS y someter el control de la exploración del crudo en aguas profundas - el Pré-Sal- a las transnacionales son también algunos elementos importantes. 
Por lo tanto, es fundamental comprender estos procesos como un complejo conjunto integrado de acciones, dentro del cual Cuba ocupa un papel central, por su posición estratégica y principalmente por su simbología épica de resistencia y dignidad. En ese sentido, son extremadamente importantes todos los esfuerzos para desestabilizar a los discursos que fundamentan y legitiman el rol de Estados Unidos como los valedores ${ }^{32}$ universales de los derechos humanos y de la democracia. Debemos tener en cuenta lo que realmente quieren decir los sucesivos mandatarios estadounidenses cuando afirman su "noble" intención de llevar a Cuba y al resto del planeta la democracia y los derechos humanos. Esa fue la intención de este trabajo.

Finalmente, parece bastante sensato afirmar que la mayor amenaza a la democracia y a los derechos humanos en Nuestra América $-\mathrm{y}$ en el mundo- sigue siendo precisamente la mercantilización de todos los aspectos de la vida, incluyendo los bienes más básicos para la supervivencia (que algunos insisten en denominar como "derechos") y los mecanismos de participación y decisión política (que algunos insisten en poner a control y servicio de las mayorías populares). Los Estados Unidos - no solo por todo el horror que han causado en nuestra historia, sino también por lo que siguen haciendo en el presente y lo que podrán hacer en el futuroson la representación más brutal de esa amenaza en los días actuales. 


\section{NOTAS}

${ }^{1}$ Doutorando em "Desarrollo y Ciudadanía: Derechos Humanos, Igualdad, Educación e Intervención Social", oor la Universidad Pablo de Olavide (Sevilla, España). Mestre em em Filosofia pela PUCRS. Bolsista da Coordenação de Aperfeiçoamento de Pessoal de Nível Superior (CAPES, Brasil).E-mail: prvitoria@gmail.com.

${ }^{2}$ La invasión mercenaria por Playa Girón (15 a 19 de abril de 1961) comprendió bombardeos aéreos, intentos de desembarco por tierra, un plan de alzamiento, terrorismo, sabotaje, radioemisión de propaganda política contrarrevolucionaria, desinformación militar y guerra psicológica dirigida a la población cubana. (SÁNCHEZ-PARODI, 2010).

${ }^{3}$ Ante el fracaso de Playa Girón, Estados Unidos pone en marcha la Operación Mangosta, que tenía por objetivo liquidar en pocos meses la Revolución Cubana. En un lapso de 14 meses, se registraron 5780 acciones terroristas, de ellas 716 sabotajes de envergadura contra objetivos económicos (ZALDÍVAR, 2004). La inminencia de una nueva investida militar estadounidense contra Cuba condujo a la Crisis de Octubre, con la estratégica y disuasiva instalación de cohetes soviéticos de medio alcance en territorio cubano.

${ }^{4}$ Se estima que los atentados terroristas realizados contra Cuba desde el triunfo de la Revolución, muchos de los cuales comprobadamente planificados por el gobierno de Estados Unidos, han dejado un saldo de 3478 muertos y 2099 discapacitados de por vida, además de un incontable número de heridos. (CASTRO, R., 2015).

${ }^{5}$ Según el documental británico 638 Ways to Kill Castro (2006), dirigido por Dollan Cannell, se han contabilizado hasta esa fecha seiscientos treinta y ocho planes de asesinato al líder de la Revolución Cubana, Fidel Castro Ruz, muchos de los cuales llegaron a ser puestos en marcha, obviamente sin suceso.

${ }^{6}$ Entre los ataques biológicos de Estados Unidos contra Cuba, se destacan: la incapacitación de trabajadores azucareros durante la zafra de 196162, utilizando medios químicos para enfermarlos; la introducción, en 1972, del virus de la fiebre porcina, que obligó a Cuba sacrificar a más de medio millón de cerdos; la introducción, entre 1979 y 1981, de cuatro 
destructivas plagas que afectaron a personas y a cultivos: la conjuntivitis hemorrágica, el dengue, la roya de la caña de azúcar y el moho azul del tabaco (solo el dengue hemorrágico, en sus primeras semanas, dañó a 200.000 personas, de las cuales murieron 158, entre ellas, 101 niños); además de otros ataques biológicos también documentados. Para una visión más profundizada, ver la Tribuna abierta de la Revolución en mesa redonda instructiva, transmitida por la televisión cubana en 8 de diciembre del 2000, fuente de las informaciones arriba. Transcripción disponible en: http://mesaredonda.cubadebate.cu/wp-content/uploads/2014/10/Tab-298-12-00.pdf

${ }^{7}$ Según un estudio de Narciso Viera (citado por ZALDÍVAR, 2004), de 1990 a 1999, "además de la radio y televisión mal llamadas "José Martí", participaron en la propaganda anticubana 6 emisoras de onda media, una en VHTF (FM), y un total de 65 fonías contrarrevolucionarias con un promedio anual para cada una de estas últimas de 731.8 horas de emisiones, 62 de ellas en territorio norteamericano, y una en Puerto Rico, Guatemala y El Salvador, respectivamente. Tres de ellas emitieron en bandas de radioaficionados y las restantes lo hicieron en gamas pertenecientes al servicio fijo y de radiodifusión.” Sobre las agresiones mediáticas e informativas contra Cuba en la prensa española, ver Serrano, 2006.

${ }^{8}$ Sobre las dimensiones y los efectos del terrorismo económico de Estados Unidos contra Cuba, iniciado inmediatamente tras el triunfo de la Revolución, conviene mencionar una vez más la ya citada obra de Zaldívar (2004), que hace un análisis histórico minucioso de las agresiones, apoyado en consistente documentación.

${ }^{9}$ La discusión, en el marco del colonialismo ibérico, sobre la naturaleza de los indios americanos queda muy bien retratada en el célebre debate de Valladolid, envolviendo Bartolomé de las Casas y Juan Ginés de Sepúlveda. Una buena síntesis de la querella se puede encontrar en Gomes, 2007.

${ }^{10}$ El idioma inglés no tiene ninguna palabra propia para designar a las personas nacidas en Estados Unidos, con lo cual se ha consolidado el equivocado uso de la palabra "american" (americano) para referir a los estadounidenses. La apropiación del gentilicio de todo un continente por parte de una sola nación no deja de reflejar una "lamentable actitud inconsciente de superioridad”, como observa Friedman (2015). 
${ }^{11}$ En abril de 1823, Adams declaró que: "Hay leyes de gravitación política como hay leyes de gravitación física; y así como una manzana separada de su árbol por la fuerza del viento no puede, aunque quiera, dejar de caer en el suelo, así Cuba, una vez separada de España y rota la conexión artificial que la liga con ella, e incapaz de sostenerse por sí sola, tiene que gravitar necesariamente hacia la Unión norteamericana, mientras a la Unión misma, en virtud de la misma ley, le será imposible dejar de admitirla en su seno". (GONZÁLEZ MAESTREY, 2011).

${ }^{12}$ La estrategia de Estados Unidos fue la de no reconocer a los insurrectos cubanos oficialmente como beligerantes (lo que les posibilitaría ayudar a los cubanos sin enviar un ejército propio), y esperar hasta el momento en que las tropas españolas estuvieran desgastadas por la resistencia cubana que ya duraba 3 años (España también vivía situación igualmente desgastante en Filipinas). Para justificar su declaración de guerra contra España, los Estados Unidos explotan a su propio buque Maine, echándole la culpa a los españoles (estrategia que volverán a utilizar en otros momentos de su historia imperial). Al derrotar en apenas 3 meses la débil España, con apenas 379 bajas en el campo de batalla (la gran mayoría de las bajas estadounidenses -5462- se dio por la ingestión de alimentos mal conservados), los Estados Unidos imponen a los cubanos formalmente independientes la enmienda Platt que subordinaba el gobierno cubano a los intereses estadounidenses, además de la cesión del territorio de la base militar de Guantánamo, cuya aceptación fue condición para la retirada de las tropas estadounidenses de la isla (ZINN, 2005).

13 Una cronología (detallada en un mapa) del Proceso de expansión territorial de las Trece Colonias Unidas del Norte de América puede ser encontrada en Suárez Salazar y Lorenzo (2008). Entre los eventos más importantes de este proceso de expansión, podemos destacar la compra de Lousiana a Francia (1803), la toma por la fuerza de la Florida Ocidental a España (parte en 1810, parte en 1813), la compra de la Florida Oriental a España (1819), la toma por la fuerza del Texas a México (1845), la conquista de Oregon a expensas de España (1846), la toma por la fuerza de California a México (1848) y la compra del Alaska a Rusia (1867), entre otros.

${ }^{14}$ Para una visión bastante completa sobre el proceso de formación del imperio estadounidense, ver Moniz Bandeira, 2005. 
${ }^{15}$ Para mencionar un ejemplo del raciocinio (anti) “antiamericano", bastante generalizado entre los estadounidenses, ver Ceaser (2010). Este autor defiende fervorosamente que el "antiamericanismo" es un dogma, fruto de una crítica injusta, racista y envidiosa de la alta filosofía europea con relación al ascenso de Estados Unidos a la posición de primera potencia mundial. Según Ceaser, "sería un error suponer que éste ha permanecido confinado en el lugar en que fue creado", pues tendría sido asumido acríticamente por otros pueblos del mundo, como los latinoamericanos y africanos. Siguiendo a un raciocinio extremadamente superficial y arrogante, el autor trata de convertir todas las posibles críticas a las políticas o a los valores de su país en una agresión irracional, hostil y completamente injustificable.

${ }^{16}$ Sobre la asimetría de los tratados y normas comerciales internacionales y su uso como herramienta para canalizar los flujos económicos desde la periferia hacia el centro, ver Wallerstein, 2012 y también Polanyi, 2012.

${ }_{17}$ Sobre el histórico de los golpes de Estado en América Latina y el Caribe, invariablemente perpetrados con el auxilio de Estados Unidos, ver Roitman, 2013.

${ }^{18}$ Para un análisis de las numerosas estrategias de Estados Unidos para perpetrar tales violaciones a los derechos humanos de forma impune ante el derecho internacional, ver Montoya, 2006.

19 Para Walter Mignolo, "La gramática de la descolonialidad (la descolonización del ser y del saber, de la teoría política y económica) comienza en el momento en el que actores que habitan lenguas y subjetividades racializadas y negadas en su humanidad, toman conciencia de los efectos de la colonialidad del ser y del saber. La colonización del ser y del saber operó y opera desde arriba hacia abajo, desde el control de la autoridad (política) y de la economía. La descolonización del ser y del saber va desde abajo hacia arriba, de la sociedad civil activa y la sociedad política radical, hacia el control imperial de la autoridad y la economía. Es en este sentido que la gramática de la descoloniadad está funcionando, tiene que funcionar, desde abajo hacia arriba". (MIGNOLO, 2010, p. 112).

${ }^{20}$ La lectura que hago aquí de la mencionada obra de Locke sigue la lógica de argumentación de Hinkelammert (1999), siendo diferentes, sin embargo, las traducciones consultadas. 
${ }^{21}$ Me refiero a los levellers y (sobre todo) los diggers, que defendían propuestas bastante semejantes a lo que muchos años después sería conceptualizado como socialismo y terminaron duramente reprimidos por la república de Cromwell.

${ }^{22}$ Los derechos reconocidos por la Declaración de Derechos de Virgínia, 86 años más tarde, son "el gozo de la vida y la libertad, junto a los medios de adquirir y poseer propiedades, y la búsqueda y obtención de la felicidad y la seguridad".

${ }^{23}$ Como esta obra de Locke está dividida en párrafos, para facilitar la consulta (ya que existen inúmeras ediciones), en lugar de mencionar el numero de la página, citaré los párrafos correspondientes.

${ }^{24}$ Frase proferida durante la Guerra Civil estadounidense por el expresidente de este país, Abraham Lincoln, en su célebre discurso de Gettysburg, en 1863.

${ }^{25}$ Cuando aquí me refiero a la hegemonía estadounidense, no me refiero apenas al gobierno de Estados Unidos, en cuanto agente político estatalnacional, sino que al conjunto de intereses gubernamentales y corporativos transnacionales que tienen como centro de referencia y origen el territorio de Estados Unidos (lo que no quiere decir que el Estado y el capital sean una misma cosa).

${ }^{26}$ Para mencionar un ejemplo, la campaña del presidente estadounidense, Barack Obama a la reelección en 2012 ha sido la más cara de la historia. Se estima que en ella fueron gastos cerca de mil millones de dólares, todos oriundos de donaciones privadas.

${ }^{27}$ Los tres poderes públicos constituidos son concebidos como fines (y no como medios) autónomos, no sometidos al control por parte del poder constituyente. Cada uno de estos poderes posee determinados mecanismos de acceso subordinados al poder económico, los cuales aseguran un margen de seguridad para la defensa de sus intereses, siendo el mecanismo de frenos y contrapesos una importante herramienta para restringir a las transformaciones sociales más radicales.

${ }^{28}$ Los medios auxilian a la depuración de las opciones (y opiniones) más "radicales" a través de la construcción de la opinión pública y de la elección de las prioridades informativas (censura). La concepción estadounidense de democracia está íntimamente relacionada con una interpretación de la "libertad de expresión" entendida como "libertad de empresa". Una prensa 
"libre" es una prensa también financiada por las grandes corporaciones - que anuncian sus productos- $-y$, naturalmente, actúa en la defensa incondicional de sus intereses corporativos y los de sus "clientes".

${ }^{29}$ Una frase del ex-presidente estadounidense Richard Nixon, citado por Friedman (2015?), caracteriza bien ese pensamiento. Según Nixon, "la forma democrática de gobierno puede no ser siempre la mejor en todos los países, en particular en esos países latinoamericanos en los que hay una carencia absoluta de madurez política".

${ }^{30}$ Según el economista José Gregorio Piña (2013), "Guerra económica es un término que designa un conjunto de acciones encubiertas o disimuladas ejecutadas por diversos actores económicos, por lo general bajo un plan concebido por actores políticos y estrategas militares, combinadas o no con otros métodos de ataque; destinadas a afectar de manera desfavorable el desempeño de una economía nacional, bajo la apariencia de ser consecuencia necesaria de la exclusiva gestión deficiente del respectivo Gobierno Nacional; ubicadas dentro de un marco de actuación de mayor alcance, como uno de los frentes de batalla, en este caso en el desarrollo de las actividades de producción, transporte, intercambio y consumo de bienes y servicios; en el contexto de una guerra abierta o encubierta llevada a cabo por potencias externas, aliadas o no con grupos políticos externos o locales, opositores todos, que financian los costos de esas acciones económicas y que buscan derrocar a dicho Gobierno por cualquier vía, legal o ilegal, de violencia explícita o implícita; con apoyo de medios de propaganda, incluidas las empresas de comunicación social que controlen, para resaltar, magnificar y reforzar las situaciones desfavorables propiciadas por dichas acciones económicas, creando un efecto retroalimentador sobre las expectativas de los actores económicos afectados y socavando el apoyo político del Gobierno de que se trate.

31 Recientemente, como nos informa TeleSUR (2015), Wikileaks ha revelado que el gobierno de Estados Unidos viene planificando golpes de Estado en países de la región e -incluso - el asesinato del presidente boliviano Evo Morales.

32 Sobre algunas de las contradicciones de presentarse al gobierno de Estados Unidos como "valedor" de los derechos humanos en Cuba, ver artículo de Iroel Sánchez, incluido en la presente bibliografía. 


\section{REFERENCIAS}

ALONSO, A. Dosier "Cuba y Estados Unidos: los dilemas del cambio". In: Cuba Posible, 2015. Disponible en http://cubaposible. com/publicaciones?\&per_page=15. Acceso en: 31/08/2015.

ARKONADA, K. EEUU: La hegemonía no termina de morir, la fase de dominación ya ha comenzado. In: Alainet, 2015. Disponible en: http://www.alainet.org/es/articulo/169418. Acceso en: $21 / 08 / 2015$.

CANNELL, Dolan (Dirección). 638 WAYS to Kill Castro. London (UK): Silver River Productions, 2006 (DVD).

CASTRO, R. Discurso en la VII Cumbre de las Américas. In: Cubadebate, 2015. Disponible en: http://www.cubadebate.cu/ opinion/2015/04/11/raul-castro-en-la-cumbre-de-las-americashasta-hoy-el-bloqueo-contra-cuba-se-aplica-en-toda-suintensidad/\#.VeQE-SWqqko. Acceso en: 20/08/2015.

CEASER, J. W. Una genealogía del antiamericanismo. In: Dikaiosyne, Revista semestral de filosofía política de la Universidad de los Andes, no 25, 2010, p. 19-32.

FERNÁNDEZ LIRIA, C. A quien corresponda, sobre Cuba, la Ilustración y el socialismo. In: Rebelión, 2004. Disponible en: http://www.rebelion.org/docs/7097.pdf Acceso en: 11/09/2015.

FRIEDMAN, M. P. La construcción del "antiamericanismo en los Estados Unidos y la Revolución Cubana. In: Material fornecido a los estudiantes del Seminario 1512 del Consejo Latinoamericano de Ciencias Sociales, 2015. 
FRIEDMAN, M. P. Mala vecindad: el antiamericanismo y Latinoamérica. In: Material fornecido a los estudiantes del Seminario 1512 del Consejo Latinoamericano de Ciencias Sociales, $201 ?$.

GOMES, R. A. Análise do debate entre Las Casas e Sepúlveda Valladolid, 1550-1551. In: Revista do Tribunal Regional Federal da $1^{a}$ Região, 19(4), 2007, p. 77-125.

GONZÁlez MAestrey, R. A. La Política de EE.UU. hacia Cuba (1800-1959), 2011. In: Instituto Superior de Relaciones Internacionales "Raúl Roa García". Disponible en: http://www. isri.cu/publicaciones/articulos/2011/boletin_0311.pdf Acceso en: $31 / 08 / 2015$.

GREGORIO PIÑA, J. Caracterización de la guerra económica. In: Aporrea, 2013. Disponible en: http://www.aporrea.org/tiburon/ a173811.html. Acceso en: 20/01/2016.

HERRERA FLORES, J. La Reinvención de los derechos humanos.

HINKELAMMERT, F. La inversión de los derechos humanos: El caso de John Locke. In: Revista Pasos, nº 85, 1999, p. 28-47.

KARG, J. M. La guerra sucia y el financiamiento contra Evo Morales. In Telesur, 2016. Disponible en: http://www.telesurtv. net/bloggers/La-guerra-sucia-y-el-financiamiento-contraEvo-Morales-20160215-0003.html. Acceso en: 20/02/2016. 
LAMRANI, SALIM. Fidel Castro, Cuba y los Estados Unidos: conversaciones con Ricardo Alarcón de Quesada, Presidente de la Asamblea Nacional del Poder Popular. La Habana: Editorial José Martí, 2007.

LOCKE, J. Segundo Tratado Sobre el Gobierno Civil: Un ensayo acerca del verdadero origen, alcance y fin del Gobierno Civil. Madrid: Tecnos, 1994.

MONIZ BANDEIRA, L. A. Formação do império americano: da guerra contra a Espanha à guerra no Iraque. Rio de Janeiro: Civilização Brasileira, 2005.

MONTOYA, R. La impunidad imperial: cómo Estados Unidos legalizó la tortura y "blindó" ante la justicia a sus militares, agentes y mercenarios. La Habana: Editorial de Ciencias Sociales, 2006.

MORGENFELD, L. Estados Unidos-Cuba: un giro histórico que impacta sobre América Latina y el Caribe. In: Crítica y emancipación: Revista Latinoamericana de Ciencias Sociales, $\mathrm{n}^{\circ}$ 12, 2015, p. 103-145.

MIGNOLO,W.Desobedienciaepistémica:retóricadelamodernidad, lógica de la colonialidad y gramática de la descolonialidad. Buenos Aires: Ediciones del Signo, 2010.

MIGNOLO, W. Historias locales/diseños globales: colonialidad, conocimientos subalternos y pensamiento fronterizo. Madrid: Akal, 2013. 
POLANYI, K. A grande transformação. Rio de Janeiro: Elsevier, 2012.

QUIJANO, A.; WALLERSTEIN, I. La americanidad como concepto, o América en el moderno sistema mundial. Revista Internacional de Ciencias Sociales (RICS), vol. XLIV, n. 4, 1992, p. 583-591.

ROITMAN ROSENMANN, M. Tiempos de oscuridad: historia de los golpes de Estado en América Latina. Madrid: Akal, 2013.

SÁNCHEZ, I. El valedor de los derechos humanos en Cuba. In: La Pupila Insomne, 2015. Disponible en: https://lapupilainsomne. wordpress.com/2015/07/29/el-valedor-de-los-derechoshumanos-en-cuba-video/. Acceso en: 21/08/2015.

SÁNCHEZ-PARODI, Ramón. Cuba-USA: diez tiempos de una relación. México, D.F.: Ocean Sur, 2010.

SANTOS, B. S. Para além do pensamento abissal: das linhas globais a uma ecologia de saberes. In: SANTOS, B. S.; MENEZES, M. P. (eds.), Epistemologias do Sul. Coimbra: Almedina, 2009.

SERRANO, P. Juego Sucio: una mirada a la prensa española de hoy. La Habana: Editorial José Martí, 2006.

SUÁREZ SALAZAR, L.; GARCÍA LORENZO, T. Las relaciones interamericanas: continuidades y cambios. Buenos Aires: CLACSO, 2008. 
TELESUR. Wikileaks:EE.UU. planea golpes de Estado en América Latina. In: Telesur, 2015. Disponible en: http://www.telesurtv.net/ news/Wikileaks-EE.UU.-planea-golpes-de-Estado-en-AmericaLatina--20151002-0025.html. Acceso en 20/01/2016.

TRIBUNA ABIERTA de la Revolución en Mesa Redonda instructiva. Debate transmitido por la televisión cubana. In: Cubadebate, 2010. Transcripción disponible en: http:// mesaredonda.cubadebate.cu/wp-content/uploads/2014/10/Tab29-8-12-00.pdf. Acceso en 20/08/2015.

WALLERSTEIN, I. El capitalismo histórico. Madrid: Siglo XXI, 2012.

WEBER, M. A ética protestante e o espírito do capitalismo. São Paulo: Companhia das Letras, 2007.

ZALDÍVAR DIÉGUEZ, A. Bloqueo: el asedio económico más prolongado de la historia. La Habana: Editorial Capitán San Luis, 2004.

ZINN, H. Las raíces de la política de los Estados Unidos hacia Cuba. In: LAMRANI, S. (ed.), EEUU contra Cuba: la guerra contra el terrorismo y el caso de los cinco. Barcelona: El Viejo Topo, 2005. 